\title{
LETTERS
}

\section{Open secret: Time of day matters in clinical practice}

I appreciate the research effort to compare clinical performance during different times of day. ${ }^{1}$ However, I believe it is an open secret, at least to many physicians, that clinical services differ depending on time of the day. During on-call hours, those providing consulting services have limited availability and must prioritize their work. It is not surprising that patients arriving late at night receive a different level of services than those who arrive during the day.

When I started my residency training in Canada as an international medical graduate (IMG), the IMG director suggested "paging etiquette" to be included in the induction training for IMGs. That was a fair suggestion, as I have observed that some new graduates, regardless of their origin, are unaware of when not to page other services. It may be an unwritten rule that we avoid paging certain consulting services for trivial matters late at night, as they each have only 1 home-call resident cross-covering multiple sites. Many graduates would eventually learn their paging etiquette through work experience.

Nevertheless, I find that the public often has the misconception that hospital services are available 24/7. I hear patients and their family members complaining about wait times at the emergency department late at night. Collaboration between patients and physicians is a 2-way street. Perhaps, to improve collaboration, we should be more transparent about the availability and on-call hours of various services. This may help patients, not including critically unwell ones, in their deliberations on when to visit hospitals for nonurgent matters. ${ }^{2}$

\section{Eugene Y.H. Yeung MD MSc}

Resident physician, Faculty of Medicine, University of Ottawa, Ottawa, Ont.

Cite as: CMAJ 2019 December 2;191: E1339. doi: 10.1503/cmaj.73768

\section{References}

1. Shuchman M. Does time of day matter in clinical practice? CMAJ 2019;191:E1063.

2. Afilalo M, Guttman A, Colacone A, et al. Emergency department use and misuse. J Emerg Med 1995; 13:259-64.

Competing interests: None declared. 